Article

\title{
Repellency of Plant Extracts against the Legume Flower Thrips Megalurothrips sjostedti (Thysanoptera: Thripidae)
}

\author{
Andnet Abtew ${ }^{1,2,3, *}$, Sevgan Subramanian ${ }^{1}$, Xavier Cheseto ${ }^{1}$, Serge Kreiter ${ }^{2}$, \\ Giovanna Tropea Garzia ${ }^{3}$ and Thibaud Martin ${ }^{1,4}$
}

1 International Centre of Insect Physiology and Ecology (icipe), Nairobi 30772, Kenya; E-Mails: ssubramania@icipe.org (S.S.); xcheseto@icipe.org (X.C.); thibaud.martin@cirad.fr (T.M.)

2 Montpellier SupAgro, UMR CBGP CIRAD/INRA/IRD/SupAgro, Campus International de Baillarguet, CS 30016, Montferrier-sur-Lez 34988, France; E-Mail: serge.kreiter@supagro.fr

3 Dipartimento di Agricoltura, Alimentazione e Ambiente (Di3A), University of Catania, Via Santa Sofia 100, Catania 95123, Italy; E-Mail: gtgarzia@unict.it

4 Centre de coopération internationale en recherche agronomique pour le dévelopement (CIRAD), UPR HORTSYS, Montpellier F-34398, France

* Author to whom correspondence should be addressed; E-Mail: abayleyegn@icipe.org; Tel.: +254-716-431-458; Fax: +254-208-632-001/2.

Academic Editors: Michael J. Stout, Jeff Davis, Rodrigo Diaz and Julien M. Beuzelin Received: 11 February 2015 / Accepted: 11 June 2015 / Published: 26 June 2015

\begin{abstract}
Megalurothrips sjostedti Trybom is an important pest of cowpea (Vigna unguiculata L.) in Africa. To propose an alternative to chemical control, the repellency of 24 plant extracts was evaluated against adult female thrips of M. sjostedti in the laboratory. Plant extracts in ethanol were separately applied on a filter paper disk in a still air visual cue olfactometer. The results showed highly significant differences in repellency among extract type, concentration and their interactions. We classified the level of repellency into four categories as strong, good, moderate and weak or non- repellent based on hierarchical ascendant classification. We identified Piper nigrum, Cinnamomum zeylanicum, Cinnamomum cassia as strong repellents. Five extracts were classified as good, eight as moderate and the remaining eight extracts were weak or non-repellent. Repellency of the extracts increased with the concentration suggesting that the behavioral response of M. sjostedti was dose-dependent. Mono- and sesquiterpene hydrocarbon compounds from seven highly repellent extracts were identified by gas chromatography-mass spectrometry (GC/MS). The use of repellent extracts could be useful in developing integrated pest management strategies for thrips on legume crops. In
\end{abstract}


this regard, the specific modes of action of the identified compounds need to be investigated to incorporate them into the existing crop protection strategies.

Keywords: plant extracts; repellency; Megalurothrips sjostedti; Olfactometer; Piper nigrum

\section{Introduction}

The Legume Flower Thrips (LFT), Megalurothrips sjostedti Trybom (Thysanoptera: Thripidae), is one of the most serious insect pests of leguminous plants including cowpea in tropical Africa [1-4]. Thrips occur on legumes in every growing season, and their direct feeding causes destruction of buds and flowers as well as malformations of pods [5]. Yield losses ranging from $20 \%$ to $100 \%$ have been reported on cowpea (Vigna unguiculata L.) from different areas of Africa where modern pest control measures are absent $[1,4]$.

Currently, the control of M. sjostedti in Sub-Saharan African countries relies heavily on synthetic insecticide application [6]. The indiscriminate use of these chemicals has given rise to problems such as resistance of the legume pests to insecticides [7,8], accumulation of toxic residues in food, health risks to the consumer and livestock and environmental contamination $[7,9,10]$. As a result, there is an urgent need to develop alternatives, which are safe, effective, biodegradable and highly selective. Pesticides from plant-based extracts have been suggested as a better alternative to synthetic insecticides [11].

Plant extracts contain many secondary metabolites that act as repellents, feeding deterrents and toxins, which have a role in defense against herbivores, pests and pathogens [12]. These secondary metabolites are released in the form of plant volatiles. Plant extracts are a complex mixture of general leaf volatiles, found in most plant species with more specific components that are shared by some plant species groups [13]. Essential oils generally consist of several constituents produced as secondary plant metabolites, the majority of which are terpene hydrocarbons, polyphenolic compounds and alkaloids [14]. Essential oils from different plant species are an important source of repellents. These odors have been extensively tested for safety and toxicity and have shown no deleterious effects on beneficial insects and are therefore considered to be one of the new means of crop protection $[15,16]$. Hence the use of essential oils for pest management is becoming popular, and many new applications are under investigation [13,17-20].

The release of repellent volatiles into the air by associated plants may disrupt the olfactory orientation of insects such as thrips [21]. Integrating naturally occurring repellent volatiles that defend plants by irritating insects and thereby leading to them spending a shorter time period in a treated area may help reduce insect damage to crops [22]. However, profound knowledge about the behavioral response of the target pest to the specific compound is a precondition for successful utilization of biologically active secondary plant compounds in crop protection strategies [18]. Although several repellent plant extracts and essential oils have been identified against onion thrips and western flower thrips [13,20], there is limited information on the use of repellents against $M$. sjostedti.

Thus, the aim of our study was to investigate potential repellent plant extracts, which could be integrated for the management of thrips in grain legumes and to characterize constituent volatiles released from highly repellent extracts. Integrating repellents that modify pest behavior in conventional legume flower 
thrips management strategies might improve efficacy in the management of thrips in the small holder farmers in Sub-Saharan African countries.

\section{Experimental Section}

\subsection{Insect Culture and Rearing}

The initial culture of adult M. sjostedti was field-collected from pigeon pea, Cajanus cajan (L.) Millsp. in Matuu, Yatta district, Kenya $\left(1^{\circ} 16^{\prime} \mathrm{N} ; 37^{\circ} 53^{\prime} \mathrm{E} ; 1246 \mathrm{~m}\right.$ a.s.1.). The thrips were subsequently reared in ventilated plastic jars provided with French bean (Phaseolus vulgaris L.) pods as described by Ekesi et al. [3]. The insect cultures were maintained in a laboratory at icipe, Nairobi, Kenya at $26 \pm 2{ }^{\circ} \mathrm{C}$; $60 \% \pm 5 \% \mathrm{RH}$ and $12 \mathrm{~L}: 12 \mathrm{D}$ photoperiod. Bean pods containing fresh thrips eggs were transferred to new jars to obtain adult thrips of known age. Adult female thrips (four to five days old) were used in the bioassays. To avoid behavioral bias prior to experimentation, adult thrips were conditioned for half a day without beans in empty jars.

\subsection{Olfactometer Bioassay}

To compare repellent effects of plant extracts against $M$. sjostedti, we adapted a simple tube still-air visual and odor cue olfactometer used by Deletre et al. $[23,24]$ as detailed in Figure 1 . The olfactometer measured $20 \mathrm{~cm}$ in length and $0.8 \mathrm{~cm}$ internal diameter. The tube was divided into three equally partitioned sections: top, middle and bottom. The top section of the tube was covered with a blue colored 3M Vinyl electrical tape (Taiwan Scotch ${ }^{\mathrm{TM}}$ ) with a size of $2.4 \mathrm{~cm} \times 4.5 \mathrm{~cm}$ as a visual cue (Figure 1 ). The bioassay was carried out in a completely randomized design (CRD) experimental set up at room temperature $\left(26 \pm 2{ }^{\circ} \mathrm{C}\right.$ ) inside a fume hood (Telstar BIO II) illuminated with fluorescent light. All seven olfactometer tubes were placed vertically on a test tube rack, parallel to each other inside the hood. The still-air visual cue olfactometer used in the study provided a combination of visual (blue color) and olfactory cues (plant extracts at different concentrations) in the test for repellency. A combination of visual and olfactory cues is involved in responses of thrips to host cues [25,26] including M. sjostedti [27].

Plant extracts tested in repellency bioassays were sourced from different suppliers as listed in Table 1. Aliquots $(3 \mu \mathrm{L})$ of plant extracts at three selected concentrations prepared in absolute ethanol $(0.01 \%$, $0.1 \%$ and $1 \%$ ) were applied on a piece of filter paper $(\varnothing 0.8 \mathrm{~cm})$ using a pipette (Finnpipette ${ }^{\circledR} 2-20 \mu \mathrm{L}$ Thermo Labsystems, Vantaa, Finland ) and placed at the top end part of the tube. Ten female M. sjostedti thrips were released at the bottom end of each tube using a small aspirator. The top end of the tube was closed with a rubber cap to prevent the odor from escaping whereas the other end was closed using a silk micro-screen fine mesh to avoid escaping of the insects and ensure ventilation. The number of insects in the three parts was counted 5 and $10 \mathrm{~min}$ after introduction. Seven replicates were run for each treatment, which were comprised of different concentrations of plant extracts. Absolute ethanol (Scharlad S.L., Spain), which was used as solvent for the plant extracts was used as a control in each experiment. The treatments were only different doses of odor cues, and the visual cue was the same for all treatments and controls. Since the experiments were repeated at different times, the control solution was run with each experiment. To avoid a dose effect, a new cohort of M. sjostedti was assayed for each concentration taken from the batch of starved and conditioned adult thrips. 


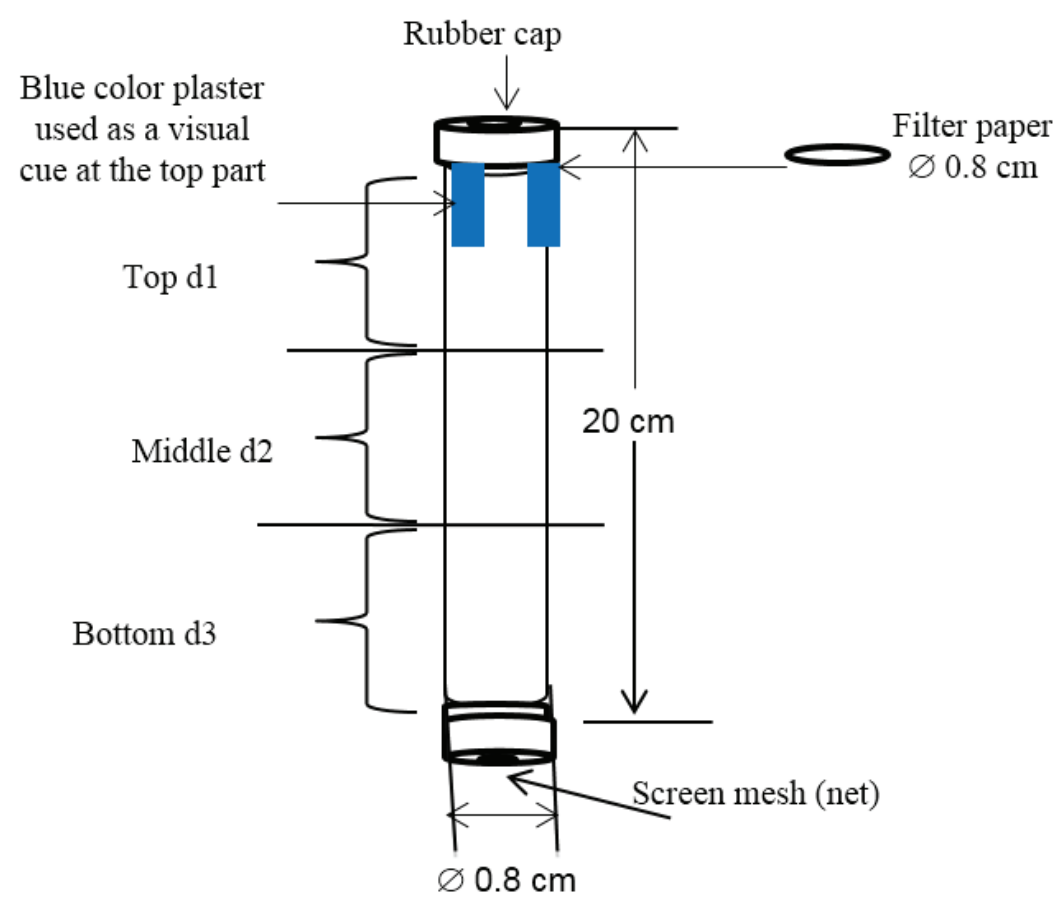

Figure 1. Schematic representation of simple tube still-air visual and odor cue olfactometer.

\subsection{Data Collection}

To determine repellency, the number of thrips was recorded for the three sections of the tube 5 and $10 \mathrm{~min}$ after odor introduction. Based on the observations, mean repellency was estimated as described below:

$$
S=\left(\left(m d T^{*} \mathrm{t}\right)+(m \mathrm{dM} * \mathrm{~m})+\left(m \mathrm{~B}^{*} \mathrm{~b}\right)\right) / \mathrm{n}
$$

where $S$ is the mean repellency per thrips for each extract or essential oil, mdT is the mean distance for the top section $=3.3 \mathrm{~cm}, \mathrm{mdM}$ is the mean distance of thrips movement for the middle section $=10.0 \mathrm{~cm}, \mathrm{mdB}$ is the mean distance of thrips movement for the bottom section $=16.5 \mathrm{~cm}, \mathrm{t}$ is the mean number of insect count at the top, $m$ is the number of insect count at the middle, $b$ is the number of insect count at the bottom and $n$ is the total number of insects per tube $(n=t+m+b)$.

\subsection{GC-MS Analysis}

Aliquots $(1 \mu \mathrm{L})$ of samples from the top seven repellent plant extracts from the olfactometer assay, prepared at a concentration of $1000 \mu \mathrm{g}$ were analyzed with gas chromatography (GC) (Agilent 7890A) capillary column (HP-5, $30 \mathrm{~m}, 0.25 \mathrm{~mm}$, i.d. $0.25 \mu \mathrm{m}$ ) directly coupled to a mass spectrometer (MS) (Agilent, Palo Alto, CA, USA) to identify the component compounds of the extracts. Ionization was performed by electron impact $\left(70 \mathrm{eV}, 230{ }^{\circ} \mathrm{C}\right)$. The oven temperature was maintained at $35^{\circ} \mathrm{C}$ for $3 \mathrm{~min}$ and then programmed at $10{ }^{\circ} \mathrm{C}$ to $285^{\circ} \mathrm{C} \cdot \mathrm{min}^{-1}$. The carrier gas was helium at a flow rate of $1.25 \mathrm{~mL} \cdot \mathrm{min}^{-1}$. Compounds were identified by comparison of retention indices and mass spectra with those of authentic standards. In the absence of corresponding reference compounds, structures were proposed on the basis of MS fragmentation pattern combined with reference spectra in the database (NIST 05, NIST 08, Adams and chemical). 
Table 1. Names and sources of the plant extracts used for the repellency experiment.

\begin{tabular}{|c|c|c|c|c|c|}
\hline No & Common Name & Scientific Name & Family & Extract Type, Plant Part Used & Supplier, Country \\
\hline 1 & African blue basil & Ocimum kilimandscharicum & Lamiaceae & Essential oil, leaf & icipe-Bioprospecting unit, Kenya \\
\hline 2 & Black pepper & Piper nigrum & Piperaceae & Essential oil, seed & IBMM $^{1}$, France \\
\hline 3 & Ceylon cinnamomum & Cinnamomum zeylanicum & Lauraceae & Essential oil, inner bark & Nactis, France \\
\hline 4 & Chinese cinnamomum & Cinnamomum cassia & Lauraceae & Essential oil, bark & Huiles \& Sens, France \\
\hline 5 & Citronella & Cymbopogon nardus & Poaceae & Essential oil, leaf & Burgess \& Finch, South Africa \\
\hline 6 & Conyza & Conyza newii & Asteraceae & Essential oil, leaf & icipe-Bioprospecting unit, Kenya \\
\hline 7 & Coriander & Coriandrum sativum & Umbelliferae & Essential oil, seed & Fabster, France \\
\hline 8 & Dill & Anethum graveolens & Apiaceae & Essential oil, seed & IBMM, France \\
\hline 9 & Eucalyptus & Eucalyptus globulus & Myrtaceae & Essential oil, leaf & Huiles \& Sens, France \\
\hline 10 & Geranium & Pelargonium graveolens & Geraniaceae & Essential oil, leaf & IBMM, France \\
\hline 11 & Ginger & Zingiber officinale & Zingiberaceae & Essential oil, root & Burgess \& Finch, South Africa \\
\hline 12 & Lemon & Citrus limon & Rutaceae & Essential oil, fruit & Capua, Italy \\
\hline 13 & Lemon grass & Cymbopogon citratus & Poaceae & Essential oil, leaf & Burgess \& finch, South Africa \\
\hline 14 & Lemon savory & Satureja biflora & Lamiaceae & Essential oil, leaf & icipe-Bioprospecting unit, Kenya \\
\hline 15 & Marjoram & Origanum majorana & Labiatae & Essential oil, leaf & Burgess \& Finch, South Africa \\
\hline 16 & May chang & Litsea cubeba & Lauraceae & Essential oil, fruit & IBMM, France \\
\hline 17 & Myrrha & Commiphora myrrha & Burseraceae & Essential oil, oleoresin-gum & Burgess \& Finch, South Africa \\
\hline 18 & Neem & Melia azadirachta & Meliaceae & Vegetable oil, seed & Huiles \& Sens, France \\
\hline 19 & Pennyroyal & Mentha pulegium & Lamiaceae & Essential oil, leaf & IBMM, France \\
\hline 20 & Rosemary & Rosmalinus officinalis & Lamiaceae & Organic floral water, leaf & Huiles \& Sens, France \\
\hline 21 & Savory & Satureja abyssinica & Lamiaceae & Essential oil, leaf & icipe-Bioprospecting unit, Kenya \\
\hline 22 & Solidage & Solidago canadensis & Asteraceae & Essential oil, flower & Huiles \& Sens, France \\
\hline 23 & Thyme (wild) & Thymus satureioides & Lamiaceae & Essential oil, flower & Huiles \& Sens, France \\
\hline 24 & Thyme (common) & Thymus vulgaris & Lamiaceae & Essential oil, leaf & Burgess \& Finch, South Africa \\
\hline
\end{tabular}

${ }^{1}$ IBMM —-Institut des Biomole'cules Max Mousseron, Montpellier, France. 


\subsection{Quantification of Terpenes}

GC-MS in full scan mode was used to detect terpenes in the oil and plant extracts. Serial dilutions of Limonene and Caryophyllene oxide $(1-100 \mathrm{pg} / \mu \mathrm{L})$ were analyzed by GC-MS in scan mode to generate linear calibration curves (peak area $v s$. concentration) with the following equations; Limonene $\left(\mathrm{y}=8 \mathrm{E}+06 \mathrm{x} R^{2}=0.9979\right)$ for monoterpenes and Caryophyllene oxide $(\mathrm{y}=4 \mathrm{E}+06 \mathrm{x}-2 \mathrm{E}+07$; $\left.R^{2}=0.9584\right)$ for sesquiterpenes. The two compounds were randomly selected based on their column chemistries in relation to the target class of compounds. Relative percentages of each compound in compositions of essential oils were calculated based on the corresponding areas of the identified compounds.

\subsection{Data Analysis}

The count data of thrips observed at the three sections of the olfactometer were converted to continuous data of mean repellency as detailed earlier. Data analysis was carried out using Analysis of Variance (ANOVA). Since the response to the control did not vary significantly among the different experiments, a mean control value was used in the statistical analysis. Where the ANOVA showed significant differences of the interactions between concentration and extract, pairwise comparison of the concentrations of each extract with the control was performed using the Student Newman Keuls test. The differences in thrips responses among different extracts for each dose were also tested with the control and a comparison of means was implemented using the Student Newman Keuls test.

The pooled interaction effect of plant extracts and concentrations was further explored using principal component analysis (PCA). Then, based on the similarity of their repellent effect, a hierarchical ascendant classification (HAC) on ward's algorithm was used to group the plant extracts using PCA-axes coordinates. This process yielded a binary segmentation tree (dendrogram), reflecting the hierarchy of similarities between $M$. sjostedti responses to plant extracts. The optimal number of classes in the tree was determined by the decrease of the interclass variance (branch height-Supplement Figure 1). The analyses were implemented using $\mathrm{R}$ version 3.11 ( $\mathrm{R}$ core team 2014) [28].

\section{Results}

\subsection{Olfactometer Bioassays}

Among the three observation sections of the olfactometer, $52 \%$ of the thrips were observed in the top of the olfactometer (where the visual and olfactory cues were presented), while $34 \%$ and $13 \%$ of the thrips were observed at the bottom and the middle of olfactometer, respectively, when considered irrespective of doses, extracts and time of exposure $\left(\mathrm{F}_{2,3063}=1840, p<0.001\right)$. Analysis of the mean repellency indicated that the effect of the interaction between extract type, concentration used and time on mean thrips repellence was not significant $\left(\mathrm{F}_{69,1152}=0.56, p=1\right)$. The two ways interaction effects between extract and time and concentration and time were not significant either $\left(\mathrm{F}_{23,1152}=0.88, p=0.63 ; \mathrm{F}_{3,1152}=1.94\right.$, $p=0.121$, respectively). However, the interaction between extract and concentration was highly significant $\left(\mathrm{F}_{69}, 1152=3.43, p<0.001\right)$. The main effects of concentration and extracts were highly significant; $\mathrm{F}_{3,1152}=143.3, p<0.001$ and $\mathrm{F}_{23,1152}=8.65, p<0.001$, respectively) while the main effect of time $(5 \mathrm{~min}$ and $10 \mathrm{~min})$ after odor introduction was not significant $\left(\mathrm{F}_{1,1152}=0.43, p=0.51\right)$. There 
was no significant difference in mean repellency between the two ways interaction effects, extract types and time $\left(\mathrm{F}_{23,1152}=0.88, p=0.62\right)$, and concentration and time $\left(\mathrm{F}_{3,1152}=1.94, p=0.12\right)$ and between the times of 5 and 10 min after odor introduction $\left(\mathrm{F}_{1,1152}=0.43, p=0.51\right)$.

In general, the repellency of extracts increased as the concentration of plant extract/essential oils increased from $0.01 \%$ to $1 \%$. At a lower concentration $(0.01 \%)$, the oils of P. nigrum, C. zeylanicum, C. cassia, C. citratus were significantly different in repelling $M$. sjostedti, and the repellency ranged from 9.2 to $10.3 \mathrm{~cm}$ distance from the odor source $\left(\mathrm{F}_{24,326}=5.33, p<0.001\right)$. At a $0.1 \%$ concentration, repellency of P. nigrum, C. zeylanicum, C. cassia, E. globulus, C. myrrha Z. officinale, T. vulgaris and $P$. graveolens were significantly different from the control, and repellency ranged from 9.3 to $11.3 \mathrm{~cm}$ $\left(F_{24,326}=5.15, p<0.001\right)$. At a $1 \%$ concentration, P. nigrum, C. zeylanicum, C. cassia, E. globulus, C. myrrha, T. vulgaris, M. pulegium, C. citrates, C. nardus, S. biflora, M. azadirachta, A. graveolens, $L$. cubeba, C. sativum, O. majorana, S. abyssinica and P. graveolens were significantly different from the control, and repellency ranged from 9.1 to $11.8 \mathrm{~cm}\left(\mathrm{~F}_{24,326}=5.99, p<0.001\right)$. At all three doses, T. satureioides, O. kilimandscharicum, S. canadensis, C. newii, C. limon and R. officinalis were not significantly different from the control for repellency of M. sjostedti (Table 2).

Based on the Hierarchical Ascendant Classification (HAC) analysis of repellence effects, the different plant extracts were categorized into to four classes: strong (Class 1), good (Class 2), moderate (Class 3 ) and weak or non repellent (Class 4). Piper nigrum, C. zeylanicum and C. cassia extracts were classified as strong repellents (Class 1), while C. myrrha, C. citratus, O. majorana, E. globulus and C. nardus were found to be good repellents (Class 2). Eight extracts were moderately repellent (Class 3); these were: M. pulegium, P. graveolens, T. vulgaris, S. biflora, M. azadirachta, A. graveolens, L. cubeba, and T. satureioides. As compared to the other extracts, the remaining eight extracts were weak or non repellent (Class 4). These were: C. sativum, O. kilimandscharicum, S. abyssinica, S. canadensis, Z. officinale, C. newii, C. limon and R. officinalis (Figure 2).

Table 2. Response of female Megalurothrips sjostedti to the repellent effect of 24 plant extracts at three concentrations $(0.01 \%, 0.1 \%$ and $1 \%)$ of extract solution and control on filter paper.

\begin{tabular}{|c|c|c|c|c|c|c|}
\hline \multirow{2}{*}{ S.N } & \multirow{2}{*}{ Extract } & \multicolumn{4}{|c|}{ Concentration (\%) } & \multirow{2}{*}{ SE of Mean } \\
\hline & & 0 (control) & 0.01 & 0.1 & 1 & \\
\hline & & 6.9 & & & & \\
\hline 1 & Black pepper & & $10.3 *$ & $11.3 *$ & $10.1 *$ & \pm 0.59 \\
\hline 2 & Ceylon Cinnamomum & & $9.4 *$ & $9.7 *$ & $10.5 *$ & \pm 0.35 \\
\hline 3 & Chinese Cinnamomum & & $9.5 *$ & $9.3 *$ & $11.8 *$ & \pm 0.41 \\
\hline 4 & Myrrh & & 8.7 & $9.9 *$ & $9.9 *$ & \pm 0.38 \\
\hline 5 & Lemongrass & & $9.2 *$ & 9.0 & $9.8 *$ & \pm 0.41 \\
\hline 6 & Marjoram & & 8.9 & 8.9 & $9.2 *$ & $\pm 0.43^{\mathrm{NS}}$ \\
\hline 7 & Eucalyptus & & 8.6 & $9.7 *$ & $9.5 *$ & \pm 0.46 \\
\hline 8 & Citronella & & 8.4 & 9.2 & $9.8 *$ & \pm 0.43 \\
\hline 9 & Pennyroyal & & 6.8 & 9.0 & $11.1 *$ & \pm 0.35 \\
\hline 10 & Geranium & & 7.6 & $9.3 *$ & $9.8 *$ & \pm 0.36 \\
\hline 11 & Thyme (Common) & & 7.9 & $10.1 *$ & $9.4 *$ & \pm 0.49 \\
\hline 12 & Lemon savory & & 8.1 & 8.9 & $9.7 *$ & \pm 0.42 \\
\hline
\end{tabular}


Table 2. Cont.

\begin{tabular}{|c|c|c|c|c|c|c|}
\hline \multirow{2}{*}{ S.N } & \multirow{2}{*}{ Extract } & \multicolumn{4}{|c|}{ Concentration (\%) } & \multirow{2}{*}{ SE of Mean } \\
\hline & & 0 (control) & 0.01 & 0.1 & 1 & \\
\hline 13 & Neem & & 7.7 & 8.8 & $9.6 *$ & \pm 0.28 \\
\hline 14 & Dill & & 7.3 & 9.0 & $9.4 *$ & \pm 0.38 \\
\hline 15 & Litsea & & 8.5 & 7.2 & $9.3 *$ & \pm 0.39 \\
\hline 16 & Thyme (wild) & & 6.9 & 8.9 & 8.9 & \pm 0.43 \\
\hline 17 & Coriander & & 8.5 & 8.3 & $9.3 *$ & \pm 0.36 \\
\hline 18 & African blue basil & & 8.3 & 9.1 & 6.6 & \pm 0.36 \\
\hline 19 & Savory & & 7.7 & 7.5 & $9.1 *$ & \pm 0.38 \\
\hline 20 & Solidago & & 7.7 & 7.5 & 8.3 & $\pm 0.34^{\mathrm{NS}}$ \\
\hline 21 & Ginger & & 7.6 & $9.3 *$ & 8.4 & \pm 0.37 \\
\hline 22 & Conyza & & 7.4 & 8.6 & 8.5 & $\pm 0.39^{\mathrm{NS}}$ \\
\hline 23 & Lemon & & 8.1 & 8.4 & 7.6 & $\pm 0.45^{\mathrm{NS}}$ \\
\hline \multirow[t]{2}{*}{24} & Rosemary & & 6.6 & 6.6 & 7.7 & $\pm 0.38^{\mathrm{NS}}$ \\
\hline & SE of mean & & \pm 0.43 & \pm 0.46 & \pm 0.48 & \pm 0.59 \\
\hline
\end{tabular}

Within concentrations of $0.01 \%, 0.1 \%$ and $1 \%$, asterisks " **" indicate a significant difference in thrips repellence of extracts from control. Within a row ${ }^{N S}$ indicates no significant difference in thrips repellence across concentrations for the extract, while all other extracts differed significantly for thrips repellence across concentrations (Student Newman Keul test, $p=0.05$ ).

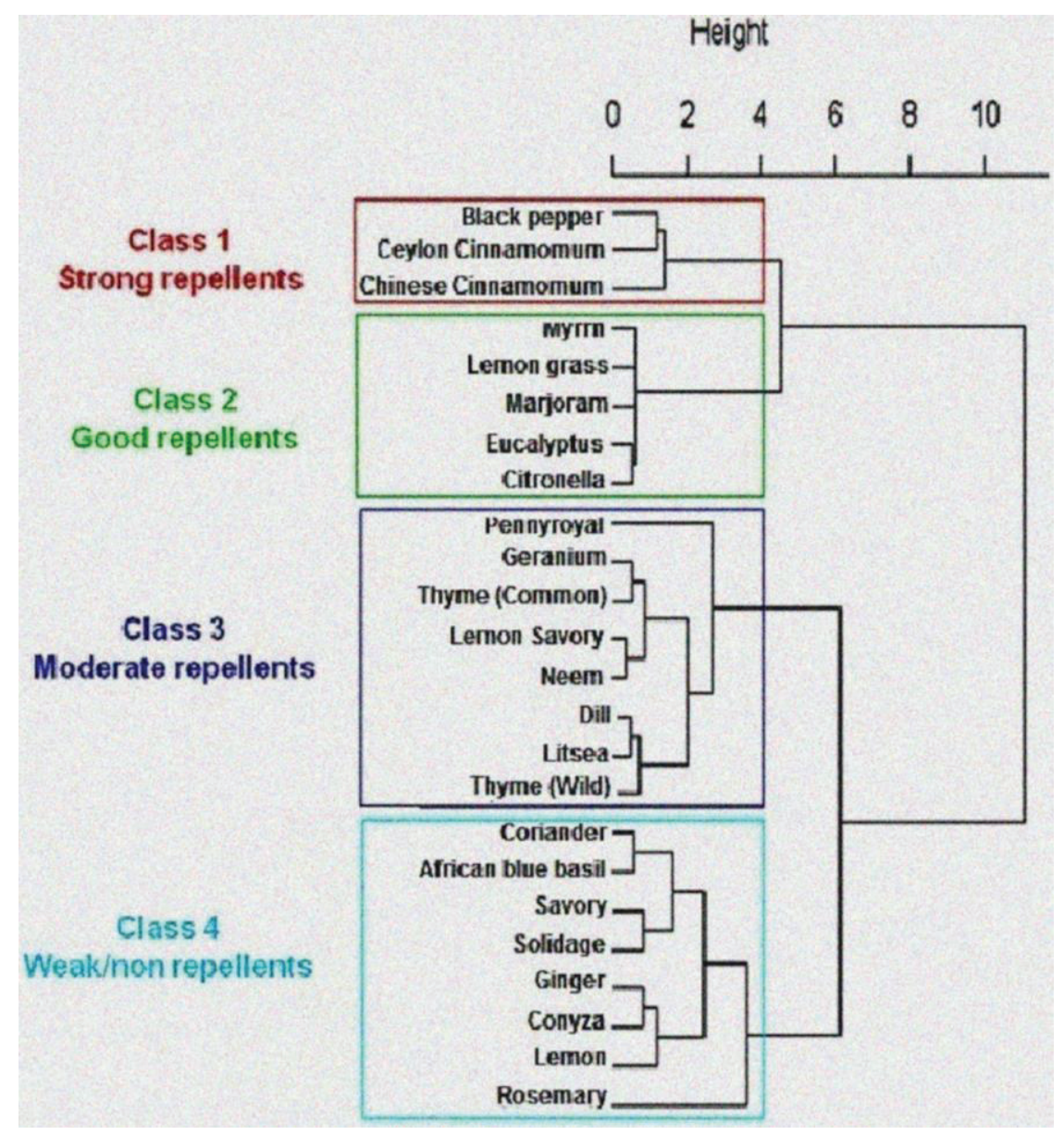

Figure 2. Dendrogram representing response of female M. sjostedti to the pooled interaction effect of extracts and concentrations. 


\subsection{Chemical Characterization}

Identification of the chemical constituents from seven highly repellent extracts showed that mono- and sesquiterpenes were the most abundant (Table 3). Fifteen compounds were identified from P. nigrum extracts. The major compounds were $\beta$-caryophyllene (45.9\%), caryophyllene oxide (12.9\%) and $\alpha$-copaene (12.3\%). Cinnamaldehyde (79.6\%), trans-cadina-1(6) and 4-diene (13.24\%) were the most abundant compounds identified from $C$. zeylanicum extract. On the other hand, cinnamaldehyde (76.7\%) and (E)-ortho-methoxy cinnamaldehyde (16.1\%) were the most abundant compounds identified from the extracts of $C$. cassia. Six compounds were identified from $C$. myrrha extracts with curzerene $(75.3 \%)$ and $\beta$-elemene (13.5\%) being the two major constituents. Five compounds were identified from extracts of E. globules of which 1,8-cineole (93.4\%) was the major compound. The major compounds identified from $C$. citrates extracts were geranial (38.3\%) and neral (33.7\%). Seventeen compounds were identified from O. marjorana with trans-sabinene hydrate (16\%), terpinene-4-ol (17.9\%) and $\gamma$-terpinene (11\%) being the major component compounds. The most frequently detected component compounds were limonene (detected from four different extracts), $\alpha$-copaene and $\beta$-caryophyllene (detected from three different extracts), $\alpha$-humulene, camphene, $\delta$-3-carene, cinnamaldehyde, $\beta$-selinene, $\alpha$-muurolene and caryophyllene oxide (detected from two different extracts) (Table 3). Major compounds of the other 17 extracts are presented in the (Supplement Table S1) from different sources.

\section{Disscussion}

The still-air visual and odor cue olfactometer used in the present study provided the opportunity to test the repellency response of legume flower thrips (LFT) to a combination of visual and olfactory cues, which is in line with the host response behavior of thrips [25,26]. However, we observed that a significantly higher proportion of LFT preferred to move to the top section of the olfactometer where the visual cue (blue color) was presented. This could be due to fact that flower/anthophilous thrips are highly attracted to flower color $[26,29,30]$. Recently LFT was reported to be highly attracted to a combination of flower volatiles and blue color, followed by blue color alone compared to yellow color with or without flower volatiles and flower volatiles alone [27]. The role of negative geotaxactic behavior as reported in thrips species such as western flower thrips [31] and thrips species infesting cereals [32] cannot be discounted but needs to be further tested for LFT. Following the top section, thrips preferred to remain in the bottom section of the olfactometer, which is due to the repellency of the extracts tested. Such an interaction of color and volatile-based cues in eliciting a response of thrips needs to be considered when further refining the still-air visual cue olfactometer, which was used for the first time in this study.

Based on the repellency response of LFT to 24 plant extracts, most of the extracts were repellent to M. sjostedti. Black pepper, Ceylon cinnamomum and Chinese cinnamomum were identified as strong repellents, while myrrh, lemon grass, marjoram, eucalyptus and citronella were classified as good repellents. To our knowledge, this is the first study looking at repellency of essential oils against M. sjostedti. Generally, the repellency of most extracts varied with concentration and indicated a dose dependent behavioral response of $M$. sjostedti. Our result corroborate previous observations on the repellent effect of essential oils and plant volatiles on other thrips species such as the western flower thrips (WFT), Frankliniella occidentalis (Pergande) [20,33,34] and the onion thrips, Thrips tabaci (Lindeman) [13,35]. 
Table 3. Compounds of the top seven plant extracts identified using gas chromatography—mass spectrometry (GC-MS).

\begin{tabular}{|c|c|c|c|c|c|c|c|c|c|}
\hline \multirow{2}{*}{ No } & \multirow{2}{*}{ Name } & \multirow{2}{*}{$\begin{array}{c}\text { Retention } \\
\text { Time (min) }\end{array}$} & \multicolumn{7}{|c|}{ Types of Essential Oils and Relative Percentage (\%) } \\
\hline & & & P. nigrum & C. zeylanicum & C. cassia & C. myrrha & C. citratus & O. marjorana & E. globulus \\
\hline $1 \diamond$ & $\alpha$-Phellandrene & 9.69 & - & - & - & - & - & 1.34 & - \\
\hline $2 *$ & $\alpha$-Pinene & 9.83 & - & - & - & - & - & 0.74 & 1.71 \\
\hline $3 *$ & Camphene & 10.21 & - & - & - & - & 1.44 & - & 0.02 \\
\hline $4^{\diamond}$ & Sabinene & 10.68 & 0.08 & - & - & - & - & 8.95 & - \\
\hline $5 *$ & Myrcene & 11.04 & - & - & - & - & 1.15 & 1.79 & - \\
\hline $6 *$ & $\delta$-3-Carene & 11.40 & 0.37 & - & - & 0.94 & - & - & - \\
\hline $7 *$ & $\delta$-2-Carene & 11.53 & - & - & - & 0.57 & - & 8.45 & - \\
\hline $8 *$ & Limonene & 11.75 & 3.43 & - & - & 2.10 & 0.72 & 3.09 & 3.09 \\
\hline $9 *$ & $\beta$-Pinene & 11.76 & - & - & - & - & - & 4.38 & - \\
\hline $10 *$ & 1,8-Cineole & 11.80 & - & - & - & - & - & - & 93.43 \\
\hline $11 *$ & (Z)-Ocimene & 11.91 & - & - & - & - & 0.40 & - & - \\
\hline $12^{\diamond}$ & $\gamma$-Terpinene & 12.31 & - & - & - & - & - & 12.7 & 1.75 \\
\hline $13^{\diamond}$ & Sabinene hydrate $=$ cis $->$ & 12.47 & - & - & - & - & - & 4.26 & - \\
\hline $14^{\diamond}$ & Terpinolene & 12.83 & - & - & - & - & - & 3.22 & - \\
\hline $15 *$ & Linalool & 13.01 & - & - & - & - & 2.06 & - & - \\
\hline $16^{\diamond}$ & Sabinene hydrate=trans- $>$ & 13.03 & - & - & - & - & - & 18.59 & - \\
\hline $17^{\diamond}$ & Menth-2-en-1-ol=cis-para-> & 13.39 & - & - & - & - & - & 1.58 & - \\
\hline $18^{\diamond}$ & (E)-Isocitral & 14.33 & - & - & - & - & 2.78 & - & - \\
\hline $19 *$ & Terpinen-4-ol & 14.33 & - & - & - & - & - & 20.79 & - \\
\hline $20 *$ & $\alpha$-Terpineol & 14.51 & - & - & - & - & 0.55 & 4.87 & - \\
\hline $21^{\diamond}$ & Neral & 15.29 & - & - & - & - & 33.66 & - & - \\
\hline $22 *$ & Linalool acetate & 15.41 & - & - & - & - & - & 2.29 & - \\
\hline $23 *$ & Geraniol & 15.43 & - & - & - & - & 5.98 & - & - \\
\hline $24^{\diamond}$ & Geranial & 15.72 & - & - & - & - & 38.32 & - & - \\
\hline $25 *$ & (E)-Cinnamaldehyde & 15.79 & - & 79.6 & 76.7 & - & - & - & - \\
\hline $26^{\ominus}$ & $\delta$-Elemene & 16.64 & 7.0 & - & - & - & - & - & - \\
\hline
\end{tabular}


Table 3. Cont.

\begin{tabular}{|c|c|c|c|c|c|c|c|c|c|}
\hline \multirow{2}{*}{ No } & \multirow{2}{*}{ Name } & \multirow{2}{*}{$\begin{array}{c}\text { Retention } \\
\text { Time (min) }\end{array}$} & \multicolumn{7}{|c|}{ Types of Essential Oils and Relative Percentage (\%) } \\
\hline & & & P. nigrum & C. zeylanicum & C. cassia & C. myrrha & C. citratus & O. marjorana & E. globulus \\
\hline $27^{\diamond}$ & $\alpha$-Cubebene & 16.82 & 1.00 & - & - & - & - & - & - \\
\hline $28^{\diamond}$ & Geranyl propanoate & 17.18 & - & - & - & - & 6.4 & - & - \\
\hline $29^{\diamond}$ & $\alpha$-Copaene & 17.20 & 12.3 & 1.49 & 0.7 & - & - & - & - \\
\hline $30^{\diamond}$ & $\beta$-Elemene & 17.40 & 2.5 & - & - & 13.52 & 1.16 & - & - \\
\hline $31 *$ & $\beta$-Caryophyllene & 17.80 & 45.9 & - & - & - & 3.78 & 3.07 & - \\
\hline $32^{\diamond}$ & Sesquithujene & 17.94 & 1.65 & - & - & - & - & - & - \\
\hline $33^{\circ}$ & (E)-Cinnamyl acetate & 18.05 & - & - & 0.74 & - & - & - & - \\
\hline $34 *$ & $\alpha$-Humulene & 18.25 & 3.05 & - & - & - & 0.95 & - & - \\
\hline $35 *$ & allo- Aromadendrene & 18.34 & - & - & 0.55 & - & - & - & - \\
\hline $36^{\circ}$ & $\gamma$-Muurolene & 18.50 & - & 2.80 & - & - & - & - & - \\
\hline $37^{\diamond}$ & $\beta$-Selinene & 18.68 & 1.73 & - & - & 7.60 & - & - & - \\
\hline $38^{\diamond}$ & Curzerene & 18.74 & - & - & - & 75.27 & - & - & - \\
\hline $39^{\diamond}$ & $\alpha$-Muurolene & 18.79 & 1.76 & 0.54 & - & - & - & - & - \\
\hline $40^{\diamond}$ & Bicyclogermacrene & 19.79 & - & - & - & - & - & 1.10 & - \\
\hline $41^{\diamond}$ & $\gamma$-Cadinene & 18.99 & - & 0.7 & - & - & - & - & - \\
\hline $42^{\diamond}$ & $\delta$ - Cadinene & 19.08 & 3.35 & - & - & - & - & - & - \\
\hline $43^{\diamond}$ & trans- Cadina-1(6),4-diene & 19.08 & - & 13.24 & - & - & - & - & - \\
\hline $44^{\diamond}$ & $\begin{array}{l}\text { (E)-Methoxy } \\
\text { cinnamaldehyde }\end{array}$ & 19.21 & - & - & 16.1 & - & - & - & - \\
\hline $45 *$ & Caryophyllene oxide & 19.86 & 12.95 & - & - & - & - & - & - \\
\hline
\end{tabular}

* Identified by comparison with authentic samples. ${ }^{\diamond}$ Identification by library data. 
Extracts from plant species from the same family did not exhibit similar levels of repellency against M. sjostedti for all plant families evaluated. For example, the repellencies of the two Cinnamomum species of the Lauraceae family were similar and categorized as strong. However, the two species of Satureja from the Lamiaceae family showed different levels of repellency where Lemon savory (S. biflora) was classified as moderate and savory (S. abyssinia) as a weak repellent (Figure 2).

The extract from $P$. nigrum was the most repellent of the 24 plant extracts tested. On a related field study Oparaeke [7] observed that the application of $10 \%$ and $20 \%$ extracts of West African black pepper, Piper guineense (Schumacher), caused a significant reduction of Megalurothrips on flowers as compared to synthetic insecticide treatment and increased pod yield on cowpea. GC-MS analysis revealed $\beta$-caryophyllene, caryophyllene oxide and $\alpha$-copaene as the major compounds in $P$. nigrum as also observed by Delétré et al. [36].

Apart from $P$. nigrum, plant extracts from the two Cinnamomum species also showed a strong repellent effect against $M$. sjostedti. Plant species of the genus Cinnamomum are fairly well known to have a repellent and toxic effect on several insect species such as the house fly Musca domestica [37], rice weevil Sitophilus zeamais [38], pulse beetle Callasobruchus maculatus [39] and mosquito, Culex quinquefasciatus [36,40,41]. Results of a chemical analysis were comparable to those found by Delétré et al. [28] who reported cinnamaldehyde at a similar quantity to be the major compound of C. zeylanicum.

Extracts from C. myrrha, which were classified as good repellents, had curzerene $(75.27 \%)$ and $\beta$-elemene (13.52\%) as major constituents. In previous studies, Commiphora rostrata Engler (Burseraceae) extracts showed repellency against the maize weevil [42], while extracts of C. myrrha and C. holtziana showed repellency against the poultry red mite, Dermanyssus gallinae (De Geer) (Mesostigmata: Dermanyssidae) [43]. The repellency of Lemongrass reported in the present study is also in line with a previous report on repellency activity of the essential oil of $C$. citratus against adults of Culex quinquefasciatus Say [44]. In terms of compositional analysis, our results were comparable to previous studies [36,45-47], where geranial and neral were identified as the major compounds in C. citratus.

Marjoram exhibited a good repellent effect against M. sjostedti. Similarly, van Tol et al. [13], reported O. majorana as a promising repellent against Thrips tabaci Lindeman (Thysanoptera: Thripidae). Moreover Yi et al. [48], observed potent fumigant toxicity of marjoram on the melon thrips, Thrips palmi Karny (Thysanoptera: Thripidae). In our study, Eucalyptus extract with 1-8 cineole as a major constituent was a good repellent against $M$. sjostedti. Oparaeke et al. [49], reported that the mean number of $M$. sjostedti was significantly reduced on plots sprayed with plant extracts mixed with Eucalyptus compared to unsprayed plots for two consecutive seasons. Similarly, Koschier and Sedy [50] reported repellency of 1,8-cineole (eucalyptol), a major constituent in rosemary oil, to female onion thrips. Citronella was also a good repellent against M. sjostedti. Similarly, Pinheiro et al. [51] reported that citronella grass, C. winterianu, showed enhanced insecticidal activity against the common blossom thrips, Frankliniella schultzei (Trybom) (Thysanoptera: Thripidae) and green peach aphid, Myzus persicae (Sulzer) (Hemiptera: Aphididae).

Among the eight moderate repellent extracts, Pennyroyal and Thyme exhibited the highest repellency against $M$. sjostedti at higher concentrations of 1\%. Yi et al. [48], reported a 23.6-fold higher toxic effect than organophosphate dichlorvos against adult melon thrips. Essential oil from Thyme was reported to be highly repellent against western flower thrips $F$. occidentalis [20].

Eight extracts, i.e., coriander, African blue basil, savory, solidage, ginger, conyza, lemon and rosemary were categorized as weak or non-repellent extracts. Similar results from Delétré et al. [36], showed that 
Lemon and Rosemary extracts did not exhibit a significant repellent effect against adults of Anopheles gambiae at a concentration of 1.0\%, while Coriander, Ginger and Solidage showed slight repellent effect against $A$. gambiae. Nevertheless, Mayeku [52] reported that Conyza essential oil showed repellency and fumigant toxicity against $A$. gambiae. Rosemary was the least repellent among all the tested extracts. However, a higher concentration (10\%) of Rosemary essential oil repelled female $T$. tabaci significantly in olfactometer bioassays [29]. Moreover, Rosemary essential oil at $0.1 \%$ and $1 \%$ concentrations decreased feeding damage of T. tabaci [53]. A possible reason for the varying results could be the low concentrations used in the present experiments as well as the composition of the Rosemary oil. For example, the major constituent in the Rosemary oil used in the olfactometer test by Koschier and Sedy [50] was 1,8-cineole (51\%), whereas, the Rosemary extracts used in the current study contained $<1 \%$ of 1,8 -cineole. Another potential reason for the varying results could be the different behavioral responses between the two thrips species M. sjostedti and T. tabaci.

The chemical composition and broad spectrum of biological activity of essential oils, even from the same source, can be inherently variable for many reasons. Factors such as plant age, plant tissues used in the distillation process and type of distillation can cause variability of chemical composition of essential oils from a plant species [44]. Likewise, variability in behavioral and biological activity can be due to the age of the targeted pest organism [50,54,55]. Biological activity could be affected by interactions among structural components in the extracts. Even minor compounds can have a critical function due to coupled effects, additive action between chemical classes and synergy or antagonism [53].

The knowledge of extent, interaction and mode of inhibition of specific compounds in plant extracts may contribute to the successful application of pest management. Although several essential oils are repellent to thrips species in the laboratory, due to high volatility, the efficacy in the field is usually low [13,19,20]. Picard et al. [20] indicated that an application method incorporating the oils into polymeric mixture coatings to protect the bioactivity of the active compounds shows a better distribution and maintains high concentrations of active compounds on the surface of the leaves for a longer period. Many plant extracts are selective to certain pests, often biodegrade to nontoxic products and have few or no harmful effects on non target organisms and the environment [49,56,57]. They also can be useful to maximize thrips control efficiency and sustainability, while minimizing negative environmental effects. Integrating host plants with repellents (push) such as intercropping, row planting or border crop may improve the effectiveness of the formulated repellents in the field. However, all these applications need further study.

\section{Conclusions}

Our results provide evidence that female $M$. sjostedti are repelled by several plant extracts and that P. nigrum, C. zeylanicum and C. cassia are strong repellents. This indicates that plant extracts or phytochemicals have potential as natural pesticides for thrips control. The repellent effect could be related to the presence of different active compounds or a blend of odors, which induce an oriented movement away from the odor source. The biological activity of the major and most abundant compounds of the tested plant extracts should be further investigated under laboratory conditions to identify and evaluate specific behavioral responses of $M$. sjostedti. This will help to identify precisely the main modes of action and levels of bioactivity of different compounds to better integrate them into management strategies for legume flower thrips. Behavioral manipulation using natural products with fewer deleterious 
effects on non-targeted organisms and the environment for the management of thrips can be considered as a new approach for pest management in grain legumes.

\section{Acknowledgments}

This study was funded by the African Union through the African Union Research Grant Contract no: AURG/108/2012 and Centre de coopération internationale en recherche agronomique pour le dévelopement (CIRAD) to which we are grateful. Additional support was provided by the European Union under the Erasmus Mundus Joint Doctorate Scholarship through Agricultural Transformation by Innovation (AgTraIn), Copenhagen. The authors also acknowledge support provided by Wilber Lwande from icipe's bioprospecting unit for the supply of four essential oils. Daisy Salifu and Emilie Delétré for statistical advice and Johnson Nyasani for his contribution in the revision of the manuscript.

\section{Author Contributions}

Andnet Abtew, Thibaud Martin and Sevgan Subramanian conceived and designed the research. Andnet Abtew and Xavier Cheseto conducted the experiments. Thibaud Martin contributed the reagents. Andnet Abtew analyzed the data, Xavier Cheseto identified the compounds. Andnet Abtew, Serge Kreiter and Giovanna Tropea Garzia wrote the manuscript. All authors read, corrected and approved the manuscript.

\section{Conflicts of Interest}

The authors declare no conflict of interest.

\section{References}

1. Singh, S.R.; Allen, D.J. Pests, diseases, resistance and protection in cowpea. In Advances in Legumes Science; Summerfield, R.J., Bunting, A.H., Eds.; Her Majestys Stationery Office: London, UK, 1980; pp. 419-443.

2. Jackai, L.E.; Adalla, C.B. Pest management practices in cowpea: A review. In Advances in Cowpea Research; Singh, B.B., Raj, D.R.M., Dashiell, K.E., Jackai, L.E.N., Eds.; Sayce Publishing: Devon, UK, 1997; pp. 240-258.

3. Ekesi, S.; Maniania, N.K.; Onu, I. Antibiosis and antixenosis of two cowpea varieties to the legume flower thrips, Megalurothrips sjostedti (Trybom) (Thysanoptera: Thripidae). J. Afr. Crop. Sci. 1998, 6, 49-59.

4. Karungi, J.; Adipala, E.; Nampala, P.; Ogenga-Latigo, M.W.; Kyamanywa, S. Pest management in cowpea. Part 3. Quantifying the effect of field pests on grain yields in eastern Uganda. Crop. Prot. 2000, 19, 343-347.

5. Abudulai, M.; Salifu, A.B.; Haruna, M. Screening of cowpeas for resistance to the flower bud thrips, Megalurothrips sjostedti Trybom (Thysanoptera: Thripidae). J. Appl. Sci. 2006, 6, 1621-1624.

6. Omo-Ikerodah, E.E.; Fatokun, C.A.; Fawol, I. Genetic analysis of resistance to flower bud thrips (Megalurothrips sjostedti) in cowpea (Vigna unguiculata [L.] Walp.). Euphytica 2009, 165, 145-154. 
7. Oparaeke, A.M. The sensitivity of flower bud thrips, Megalurothrips sjostedti Trybom (Thysanoptera: Thripidae), on cowpea to three concentrations and spraying schedules of Piper guineense Schum. \& Thonn. extracts. Plant Protect. Sci. 2006, 42, 106-111.

8. Bediako, A. Inheritance of resistance to flower bud thrips (Megalurothrips sjostedti) in cowpea. M.Sc. Thesis, Kwame Nkrumah University of Science and Technology, Kumasi, Ghana, 2012.

9. Muthomi, J.W.; Otieno, P.E.; Chemining’wa, G.N.; Nderitu, J.H.; Wagacha, J.M. Effect of chemical spray on insect pests and yield quality of food grain legumes. J. Entomol. 2008, 3, 156-163.

10. Egho, E.O. Management of major field insect pests and yield of cowpea (Vigna unguiculata (L) Walp) under calendar and monitored application of synthetic chemicals in Asaba, Southern Nigeria. Am. J. Sci. Ind. Res. 2011, 4, 592-602.

11. Isman, M.B. Botanical Insecticides: For richer, for poorer. Pest Manag. Sci. 2008, 64, 8-11.

12. Maia, F.M.; Moore, J.S. Plant-based insect repellents: A review of their efficacy, development and testing. Malar. J. 2011, doi:10.1186/1475-2875-10-S1-S11.

13. Van Tol, R.W.; Jame, D.E.; de Kogel, W.J.; Teulon, D.A.J. Plant odours with potential for a push-pull strategy to control the onion thrips, Thrips tabaci. Entomol. Exp. Appl. 2006, 12, 69-76.

14. Agostini-Costa, T.S.; Vieira, R.F.; Bizzo, H.R.; Silveira, D.; Gimenes, M.A. Chromatography and its applications. In Plant secondary metabolites; Dhanarasu, S., Ed.; In Tech Publisher: Rijeka, Croatia, 2012; pp. 131-164.

15. Plimmer, J.R. Regulatory problems associated with natural products and biopesticides. Pesticide Sci. 1993, 39, 103-108.

16. Isman, M.B. Botanical insecticides, deterrents, and repellents in modern agriculture and an increasingly regulated world. Annu. Rev. Entomol. 2006, 51, 45-56.

17. Regnault-Roger, C. The potential of botanical essential oils for insect pest control. Integr. Pest Manag. 1997, 2, 25-34.

18. Koschier, E.H. Plant allelochemicals in thrips control strategies. In Naturally Occurring Bioactive Compounds; Series: Advances in Phytomedicine Vol. 3; Rai, M., Carpinella, C.M., Eds.; Elsevier Science: Amsterdam, The Netherlands, 2006; pp. 221-249.

19. Reitz, S.R.; Maiorino, G.; Olson, S.; Sprenkel, R.; Crescenzi, A.; Momol, M.T. Integrating plant essential oils and kaolin for the sustainable management of thrips and tomato spotted wilt on tomato. Plant Dis. 2008, 92, 878-886.

20. Picard, I.; Hollingsworth G.R.; Salmieri, S.; Lacroix, M. Repellency of essential oils to Frankliniella occidentalis (Thysanoptera: Thripidae) as affected by type of oil and polymer release. J. Econ. Entom. 2012, 105, 1238-1247.

21. Den Beider, E.; Elderson, J.; Agca, I. Is olfactory orientation of Thrips tabaci disrupted by a non-host plant? Proc. Exp. Appl. Entomol. N.E.V. Amsterdam 2001, 12, 61-64.

22. Peterson, C.; Coats, J. Insect repellents_-Past, present and future. Pestic. Outlook 2001, 12, 154-158.

23. Deletre, E.; Chandre, F.; Barkman, B.; Menut, C.; Martin, T. Naturally occurring bioactive compounds from four repellent essential oils against Bemisia tabaci whiteflies. Pest Manag. Sci. 2015, doi:10.1002/ps.3987.

24. Deletre, E.; Mallent, M.; Menut, C.; Chandre, F.; Martin, T. Behavioral response of Bemisia tabaci to 20 plant extracts. J. Econ. Entomol. 2015, doi:10.1093/jee/tov118. 
25. Teulon, D.A.; Penman, D.R.; Ramakers, P.M. Volatile chemicals for thrips (Thysanoptera: Thripidae) host finding and application for thrips pest management. J. Econ. Entomol. 1993, 86, 1405-1415.

26. Terry, L.I. Host selection, communication and reproductive behavior. In Thrips as Crop Pests; Lewis, T., Ed.; CAB International: Wallingford, UK, 1997; pp. 435-475.

27. Muvea, A.M.; Waiganjo, M.M.; Kutim, H.L.; Osiemo, Z.; Nyasani, J.O.; Subramanian, S. Attraction of pest thrips (Thysanoptera: Thripidae) infesting French beans to coloured sticky traps with Lurem-TR and its utility for monitoring thrips populations. Int. J. Trop. Insect Sci. 2014, 34, 197-206.

28. R Core Team. $R$ : A language and environment for statistical computing. $R$ Foundation for Statistical Computing; R Core Team: Vienna, Austria, 2014.

29. Matteson, N.A.; Terry, L.I. Response to color by male and female Frankliniella occidentalis during swarming and non-swarming behavior. Entomol. Exp. Appl. 1992, 63, 187-201.

30. Vernon, R.S.; Gillespie, D.R. Spectral responsiveness of Frankliniella occidentalis (Thysanoptera: Thripidae) determined by trap catches in greenhouses. Environ. Entomol. 1990, 19, 1229-1241.

31. Ebssa, L.; Borgemeister, C.; Berndt, O.; Poehling, H.M. Impact of entomopathogenic nematodes on different soil-dwelling stages of western flower thrips, Frankliniella occidentalis (Thysanoptera: Thripidae), in the laboratory and under semi-field conditions. Biocontrol. Sci. Techn. 2001, 4, 515-525.

32. Holtmann, H. Untersuchungen zur Biologie der Getreide-Thysanopteren. Z. Angew. Entomol. 1962, 51, 285-299.

33. Pow, E.M.; Bennison, J.A.; Birkett, M.A.; Luszniak, M.L.; Manjunata, M.; Pickett, P.A.; Segers I.S.; Wadhams, L.J.; Wardlow, L.R.; Woodcock, C.M. Behavioural responses of western flower thrips (Frankliniella occidentalis) to host plant volatiles. In Proceedings International Symposium on VI Thysanoptera, Akdeniz University, Antalya, Turkey, 27 April-1 May 1998; pp. 121-128.

34. Koschier, E.H.; de Kogel, W.J.; Visser, J.H. Assessing the attractiveness of volatile plant compounds to western flower thrips Frankliniella occidentalis. J. Chem. Ecol. 2000, 26, 2643-2655.

35. Koschier, E.H.; Sedy, K.A.; Novak, J. Influence of plant volatiles on feeding damage caused by the onion thrips Thrips tabaci. Crop. Prot. 2002, 21, 419-425.

36. Delétré, E.; Martin, T.; Campagne, P.; Bourguet, D.; Cadin, A.; Menut, C.; Bonafos, R.; Chandre, F. Repellent, irritant and toxic effects of 20 plant extracts on adults of the malaria vector Anopheles gambiae mosquito. PLoS ONE 2013, 12, e82103.

37. Samarasekera, R.; Kosmulalage, S.K.; Indira, S.W. Insecticidal activity of essential oils of ceylon Cinnamomum and Cymbopogon species against Musca domestica. J. Essent. Oil Res. 2006, 18, 352-354.

38. Ishii, T.; Matsuzawa, H.; Vairappan, C.S. Repellent activity of common spices against the rice weevil, Sitophilus zeamais Motsch (Coleoptera, Curculionidae). J. Trop. Biol. Conserv. 2010, 7, 75-80.

39. Ratnasekera, D.; Rajapakse, R.H.S. Repellent properties of plant oil vapours on pulse beetle (Callasobruchus maculatus 1.) (Coleoptera: Bruchidae) in stored green gram (Vigna radiata walp.). Trop. Agric. Res. Ext. 2009, 12, 13-16.

40. Prajapati, V.; Tripathi, A.; Aggarwal, K.; Khanuja, S.P. Insecticidal, repellent and oviposition-deterrent activity of selected essential oils against Anopheles stephensi, Aedes aegypti and Culex quinquefasciatus Bioresou. Technol. 2005, 96, 1749-1757. 
41. Chang, K.S.; Tak, J.H.; Kim, S.I.; Lee, W.J.; Ahn, Y.J. Repellency of Cinnamomum cassia bark compounds and cream containing cassia oil to Aedes aegypti (Diptera: Culicidae) under laboratory and indoor conditions. Pest Manag. Sci. 2006, 62, 1032-1038.

42. Lwande, W.; Hassanali, A.; Mcdowell, P.G.; Moreka, L.; Nokoe, S.K.; Waterman, P.G. Constituents of Commiphora rostrata and some of their analogs as maize weevil, Sitophilus zeamais repellents. Insect Sci. Appl. 1992, 13, 679-683.

43. Birkett, M.A.; Abassi, S.A.; Krober, T.; Chamberlain, K.; Hooper, A.M.; Guerin, P.M.; Pettersson, J.; Pickett J.A.; Slade, R.; Wadhams, L.J. Antiectoparasitic activity of the gum resin, gum haggar, from the East African plant, Commiphora holtziana. Phytochemistry 2008, 69, 1710-1715.

44. Pushpanathan, T.; Jebanesan, A.; Govindarajan, M. Larvicidal, ovicidal and repellent activities of Cymbopogan citratus Stapf (Graminae) essential oil against the filarial mosquito Culex quinquefasciatus (Say) (Diptera: Culicidae). Trop. Biomed. 2006, 23, 208-212.

45. Olivero-Verbel, J.; Nerio, L.S.; Stashenko, E.E. Bioactivity against Tribolium castaneum Herbst (Coleoptera: Tenebrionidae) of Cymbopogon citratus and Eucalyptus citriodora essential oils grown in Colombia. Pest Manag. Sci. 2010, 66, 664-668.

46. Franz, A.R.; Knaak, N.; Fiuza, L.M. Toxic effects of essential plant oils in adult Sitophilus oryzae (Linnaeus) (Coleoptera, Curculionidae). Rev. Bras. Entomolo. São Paulo 2011, 55, 116-120.

47. Costa, A.V.; Pinheiro, P.F.; Rondelli, V.M.; de Queiroz, V.T.; Tuler, A.C.; Brito, K.B.; Stinguel, P.; Pratissoli, D. Cymbopogon citratus (Poaceae) essential oil on Frankliniella schultzei (Thysanoptera: Thripidae) and Myzus persicae (Hemiptera: Aphididae). Biosci. J. Uberlând. 2013, 29, 1840-1847.

48. Yi, C.G.; Choi, B.R.; Park, H.M.; Park, C.G.; Ahn, Y.J. Fumigant toxicity of plant essential oils to Thrips palmi (Thysanoptera: Thripidae) and Orius strigicollis (Heteroptera: Anthocoridae). J. Econ. Entomol. 2006, 99, 1733-1738.

49. Oparaeke, A.M.; Dike, M.C.; Amatobi, C.I. Botanical pesticide mixtures for insect pest management on cowpea, Vigna unguiculata (L.) walp plants-The legume flower bud thrips, Megalurothrips sjostedti Trybom. J. Sust. Agric. 2006, 29, 5-13.

50. Koschier, E.H.; Sedy, K.A. Labiate essential oils affecting host selection and acceptance of Thrips tabaci Lindeman. Crop. Prot. 2003, 22, 929-934.

51. Pinheiro, F.P.; Queiroz, T.V.; Rondelli, M.V.; Costa, V.A.; Marcelino, T.P.; Pratissoli, D. Insecticidal activity of citronella grass essential oil on Frankliniella schultzei and Myzus persicae. Ciênc. Agrotec. Lavras 2013, 37, 138-144.

52. Mayeku, W.P.; Omollo, N.I.; Odalo, O.J.; Hassanali, A. Chemical composition and mosquito repellency of essential oil of Conyza newii propagated in different geographical locations of Kenya. Med. Vet. Entomol. 2013, 28, 253-256.

53. Katerinopoulos, H.E.; Georgia, P.; Athanasios, A.; Nicolaos, S.; Nikolaos, R. Composition and Insect Attracting Activity of the Essential Oil of Rosmarinus officinalis. J. Chem. Ecol. 2005, 31, 111-122.

54. Chiasson, H.; Belanger, A.; Bostanian, N.; Vincent, C.; Poliquin, A. Acaricidal properties of Artemisia absinthium and Tanacetum vulgare (Asteraceae) essential oils obtained by three methods of extraction. J. Econ. Entomol. 2001, 94, 167-171.

55. Choi, W.I.; Lee, E.H.; Choi, B.R.; Park, H.M.; Ahn, Y.J. Toxicity of plant essential oils to Trialeurodes vaporariorum (Homoptera: Aleyrodidae). J. Econ. Entomol. 2003, 96, 1479-1484. 
56. Barton, A.F. Industrial use of Eucalyptus oil. In Proceedings, the Oil Mallee Profitable Landcare Seminar; Oil Mallee Association of Western Australia: Perth, Western Australia, Australia, 1999; pp. 43-54.

57. Isman, M.B. Pesticides based on plant essential oils for management of plant pests and diseases. In Proceedings of the International Symposium on Development of Natural Pesticides from Forest Resources, Seoul, Korea, 8-10 October 2001; Forest Research Institute: Seoul, Korea, 2001; pp. 1-9.

(C) 2015 by the authors; licensee MDPI, Basel, Switzerland. This article is an open access article distributed under the terms and conditions of the Creative Commons Attribution license (http://creativecommons.org/licenses/by/4.0/). 